www.jmscr.igmpublication.org

Index Copernicus Value: 79.54

ISSN (e)-2347-176x ISSN (p) 2455-0450

crossref DOI: https://dx.doi.org/10.18535/jmscr/v7i6.164

\title{
Role of Transrectal Ultrasonograpy and Colour Doppler in the Evaluation of Prostatic Carcinoma
}

\author{
Authors \\ Dr Swathi.K ${ }^{1}$, Dr Sajitha $K^{2^{*}}$, Dr Abhilash Babu ${ }^{3}$ \\ ${ }^{1}$ Resident, Dept of Radiodiagnosis, MC Kottayam \\ ${ }^{2}$ Professor, Dept of Radiodiagnosis, MCH Kottayam \\ ${ }^{3}$ Dept of radiodiagnosis, MCH Kottayam \\ *Corresponding Author \\ Dr Sajitha K \\ Additional Professor in Radiodiagnosis Govt Medical College, Kottayam, India
}

\begin{abstract}
Background: Prostate carcinoma is the fifth leading cause of death from cancer in men, accounting for about $6.6 \%$ of the total deaths in men Objectives: To evaluate the efficacy of transrectal ultrasonography in differentiating benign from malignant lesions and to assess the additional advantage of colour doppler when used in conjunction with grey scale ultrasonography.
\end{abstract}

Methodology: A prospective study was conducted in the Department of Radio diagnosis, Government Medical College, Kottayam for a period of 18 months from April 2016 to October 2017. Study population included 122 male patients with clinical symptoms or digital rectal examination suspicious of prostatic disease and / or patients with raised PSA [PSA>4ng/ml] The final imaging results were correlated with trus guided 12 core biopsy specimens or aspirated samples in cases where imaging findings were suggestive of abscess.

Results: Of the 122 cases studied, malignancy was found in $40.1 \%$ of cases and benign diseases were found in 59.9\% of cases. The sensitivity, specificity, PPV and NPV in our study with transrectal ultrasound versus colour doppler are $75.51 \%$ vs $73.47 \%$, $75.34 \%$ vs $80.82 \%, 67.27 \%$ vs $72 \%$ and $82.09 \%$ vs $81.94 \%$. Conjunction of colour doppler with grey scale ultrasound resulted in increase in sensitivity by $5 \%$ [81.63\%], specificity by 3\%.[78.08\%],

Conclusion: Transrectal ultrasound grey scale with Colour doppler imaging findings alone are not sufficient for completely excluding malignancy. It can be used as an adjunct in evaluating suspicious lesions and as a screening modality to perform targeted biopsy in elderly debilitated males who cannot withstand a regular biopsy.

Keywords: Transrectal Ultrasound; Colour doppler; Resistive Index; Prostatic carcinoma.

\section{Introduction}

Prostate carcinoma is the fifth leading cause of death from cancer in men, accounting for about $6.6 \%$ of the total deaths in men. Mortality rates are generally high predominantly in black populations and low in Asia ${ }^{1}$. Recent studies based on National Cancer Registry report that incidence of carcinoma prostate is increasing in India. 
The current methods of screening for prostate cancer include measuring serum prostate specific antigen levels, digital rectal examinations, and transrectal ultrasound. Transrectal ultrasonography is the preferred initial imaging technique because it is readily available, affordable and there is no risk of radiation exposure also .The use of high resolution color doppler imaging and tissue harmonic technology has improved cancer detection. In addition, lesiondirected target biopsy along with a biopsy of the potential route of tumor escape (such as a nearby neurovascular bundle and seminal vesicles) improved the staging of the cancer and often improved Gleason grading. The final imaging diagnosis will be correlated with histopathological examination of the specimen obtained by either TRUS guided 12 core biopsy or aspirated samples in cases where imaging findings are suspicious of abscess.

\section{Anatomy of Prostate ${ }^{1}$}

\section{Prostate zonal anatomy}

Prostate is divided into the following four glandular zones surrounding the prostatic urethra: Peripheral zone, Transition zone, Central zone, Anterior fibromuscular zone.

Prostatic carcinoma is the second leading cause of cancer related deaths worldwide.

\section{Peripheral gland lesions}

Peripheral zone lesions appear hypoechoic in 50 to $70 \%$ of cases and, isoechoic or hyperechoic in rest of the cases. Spajic et al in his study shown that Gleason score of hyperechoic cancers were higher when compared with isoechoic and hypoechoic cancers. ${ }^{3}$ Praveen kumar $\mathrm{P}$ and Chanabasappa Chavadi ${ }^{4}$ studied capsular status on 50 patients. Regular or continuous outline was observed in 35cases $(70 \%)$, was seen mainly in BPH (23 patients-65.70\%) and carcinoma prostate (8 patients-22.85\%). Irregular and interrupted capsule is seen in $30 \%$ of patients, was seen mainly in carcinoma prostate (12patients - 80\%) and BPH (3patients -20. R Malik, VK Pandya, D Naik ${ }^{5}$ demonstrated capsular breach in $60.87 \%$ of carcinoma prostate. Monzer and Yousef $^{6}$ using suprapubic USG found capsular breach in $9 / 18$ $(50 \%)$ cases whereas normal regular in $8 / 18$ (44.4\%) and capsule not visualized in $5.6 \%$ cases. Mathew et al ${ }^{7}$ found normal continuous capsule in 93\% patients with $\mathrm{BPH}$.

Griffiths et $\mathrm{al}^{8}$ reported that prostatic capsule appeared breached in 55\% cases of carcinoma prostate.

Hypoechoic lesions are more common in carcinoma of prostate $(70.00 \%)$ followed by hyperechoic and mixed echogenic lesions $(15.0 \%)^{2}$

When the entire gland is replaced with tumor, on a $\mathrm{BPH}$ background, the gland may be diffusely inhomogeneous. TRUS signs of extracapsular extension are focal bulge[ Fig 1 ], irregularity of the capsule, obliteration of the rectoprostatic angle, asymmetry of the neurovascular bundle, angulation/step-off appearance to the tumour, focal capsular retraction and or thickening, broad capsular tumour contact (>10 mm), breach of the capsule with evidence of direct tumour extension.

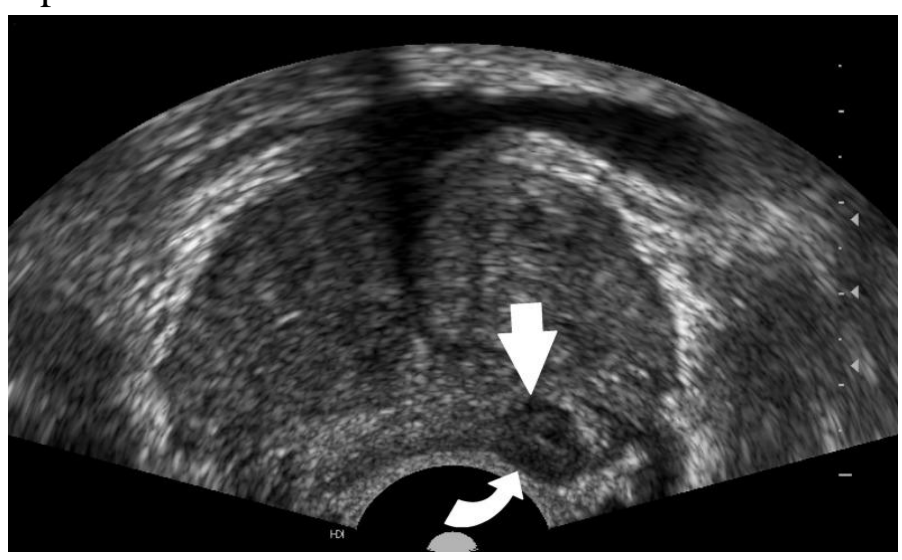

Fig 1: T3a tumour in axial TRUS

Hypoechoic lesion in left peripheral zone (thick white arrow) with focal capsular bulge (white curved arrow)

\section{Colour and power Doppler}

Doppler imaging has been evaluated for detection of neovascularity associated with cancer. Three patterns of flow changes have been noted in cancer: focal flow, increased flow around a nodule and asymmetrical flow on the cancerous side with an increase in the size and number of vessels 


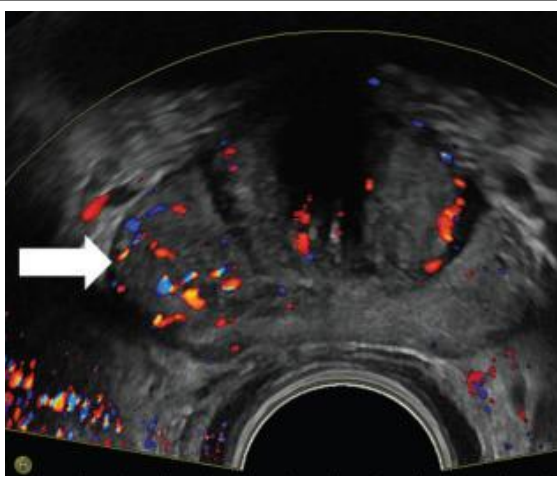

Fig 2: T3a prostatic carcinoma

Hypoechoic lesion in right base showing increased vascularity on colour Doppler.

Cho $\mathrm{J}$ and Kim $\mathrm{S}$ et al ${ }^{10}$ in their study shown that Color and power Doppler ultrasound has a sensitivity of $80 \%$, a specificity of $84 \%$, and an accuracy of $82 \%$ if we consider an increased flow signal within a peripheral zone focal hypoechoic or diffuse lesion as a sign of prostate cancer.

Sarkar $\mathrm{S}^{12}$ and Louvar $\mathrm{E}^{13}$ et al in their studies proved that the malignant lesions are hypervascular and vascularity correlates with the rise in gleason score.

Huang ST et al reported higher RI in high grade prostate cancer. $^{14}$

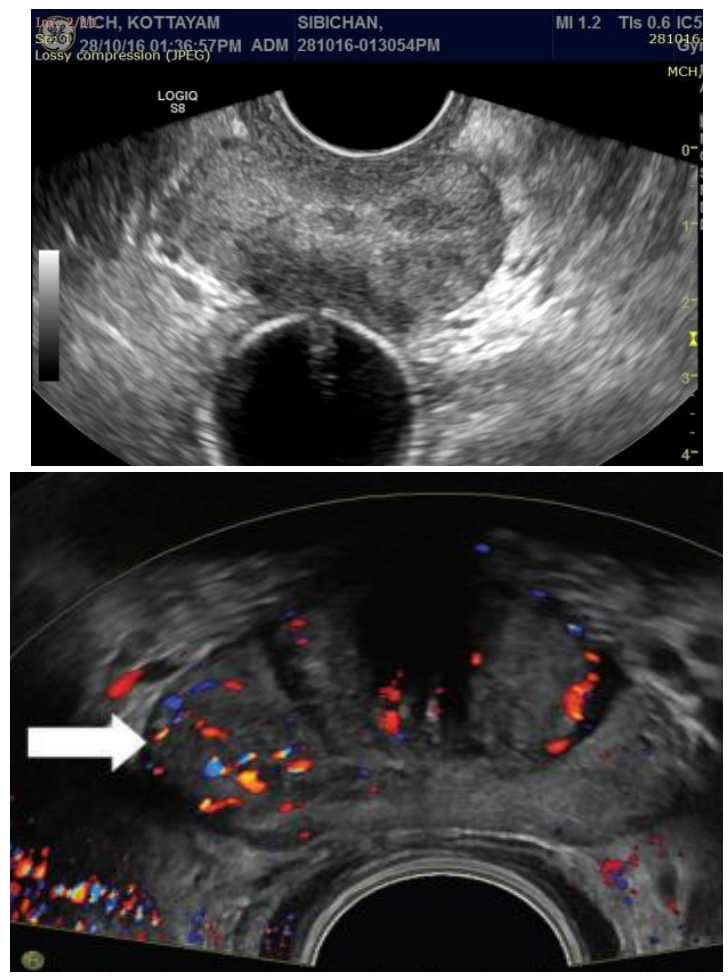

Fig 3: T3a prostatic carcinoma

Hypoechoic lesion in right base showing increased vascularity on colour doppler

Study Design; Prospective study
Study period: 18 months from April 2016 to October 2017 in Department of Radiodiagnosis, Govt. Medical College, Kottayam

\section{Sample Size: 122}

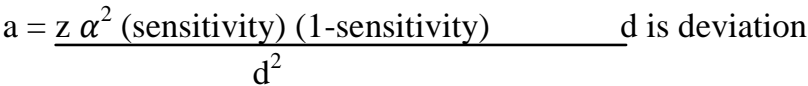

Study population: Study population include 122 patients with prostatic symptoms, and raised PSA $>4 \mathrm{ng} / \mathrm{ml}$ received in department The study was conducted in the department of Radiodiagnosis, Government Medical College Kottayam for a period of 18 months after the approval of institutional review board.

Study tools: 1. High resolution ultrasound with colour doppler [LOGIC S8], 2. Endocavity broadband transducer [IC 5-9], 3. Histopathology Report, 4. Proforma to record serial number, Name, age, sex, clinical features, radiological features \& histopathological report.

Study procedure: After cleansing enema the patient was asked to lie in a left lateral decubitus position for the scan with his right and hip knee flexed., Using adequate lubrication, the broadband 5-9MHz endocavity transducer [LOGIC S8, IC 59] was gently inserted into the rectum after covering it with a protective rubber sheath (condom).

\section{Data management and analysis}

The data was coded, verified and entered in Microsoft excel and further statistical analysis was done using SPSS software. Qualitative variable was expressed as percentages and quantitative variable was expressed as actual. The level of statistical significance is $\mathrm{p}$ value less than 0.05 .

\section{Results and Observations Imaging Findings}

Table 1: Resistive index in left capsular artery versus biopsy result

\begin{tabular}{|l|c|c|}
\hline $\begin{array}{l}\text { Resistive index in } \\
\text { left capsular artery }\end{array}$ & Benign & Malignant \\
\hline $\mathrm{N}$ & 73 & 49 \\
\hline SD & 0.12018 & 0.10368 \\
\hline Mean & 0.6858 & 0.6580 \\
\hline SE Mean & 0.01407 & 0.01481 \\
\hline Test used & \multicolumn{2}{|c|}{0.189} \\
\hline P value & NS \\
\hline Significance & \multicolumn{2}{|c|}{} \\
\hline
\end{tabular}


For right capsular artery resistive index , $\mathrm{P}$ value $=0.193$ and for left capsular artery resistive index $\mathrm{P}$ value $=0.189$ hence no statistically significant difference exist between the resistive index of capsular arteries in benign and malignant lesions.

Table 2: Final imaging diagnosis vs biopsy result

\begin{tabular}{|l|c|c|c|}
\hline \multirow{2}{*}{$\begin{array}{l}\text { Final Imaging } \\
\text { diagnosis }\end{array}$} & \multicolumn{3}{|c|}{ Nature of Lesion in Biopsy } \\
\cline { 2 - 4 } & Benign & Malignant & Total \\
\hline Benign & $57(78.1 \%)$ & $9(18.4 \%)$ & $66(54.1 \%)$ \\
\hline Malignant & $16(21.9 \%)$ & $40(81.6 \%)$ & $56(45.9 \%)$ \\
\hline Total & $73(100 \%)$ & $49(100 \%)$ & $122(100 \%)$ \\
\hline
\end{tabular}

Table 3: Malignant lesions showing infiltration

\begin{tabular}{|l|c|c|}
\hline Malignant lesions & Frequency & Percentage \\
\hline With infiltration & 17 & $34.6 \%$ \\
\hline Without infiltration & 32 & $65.4 \%$ \\
\hline Total & 49 & $100 \%$ \\
\hline
\end{tabular}

\section{Discussion}

Owing to the widespread use of imaging studies the detection rate of prostatic diseases has increased and an accurate characterization of imaging features of prostatic diseases has become more essential for management. The role of transrectal ultrasound is not only differentiating benign from malignant lesions but also to take biopsy from suspicious areas.

The purpose of the present study was to evaluate the efficacy of transrectal ultrasound in diagnosing prostatic diseases, differentiating benign from malignant lesions and to assess the additional advantage of colour doppler with spectral tracing when it was used in conjunction with grey scale ultrasound. The final imaging results was correlated with TRUS guided 12 core biopsy which included the suspicious areas also.

Age distribution of prostatic diseases: In our study group of 122 patients with prostatic diseases, the age of presentation ranged from 52 to 88 years. The mean age was 70 years. The maximum cases were in the age group $61-70$ years which was followed by the age group $71-$ 80 years. The rate of malignancy increases with age.
Imaging Findings in Transrectal Grey Scale Ultrasound

Among different TRUS characteristics, presence of focal lesion, location of lesion in peripheral gland, ill defined margins of the lesion, capsular irregularity, infiltration of lesion into the adjacent structures were found to be significantly associated with malignancy and median lobe projection was associated with benignity.

Capsular status: Regular and continuous capsule was most commonly present in $60.7 \%(n=74)$ of total cases and was seen in $(n=62) 84.9 \%$ of benign cases and $24.5 \% \quad(n=12)$ of malignant cases. Irregular and interrupted capsule was present in $39.3 \%(n=48)$ of total cases and was mainly seen in $75.5 \%$ of malignant cases $(n=37)$ and $15.1 \%(\mathrm{n}=11)$ of benign cases. Irregular and interrupted capsule was significantly associated with malignancy with $P$ value of 0.000 and Pearson chi square value of 44.883

Presence of focal lesion: Presence of solid focal lesion in TRUS grey scale with or without increased vascularity in colour doppler was considered as malignancy in this study. Totally in 58 cases, focal lesions were detected with the help of grey scale imaging.

Location of the lesion: Total number of malignant lesions diagnosed based on biopsy result is 49.Total number of lesions visualised in imaging is 36 . No lesions were visualised in about 13 cases. Among the lesions visualised, total percentage of malignant lesion visualised in central gland $=0.02 \%$; peripheral gland $=54.05 \%$; both central and peripheral gland $=43.24 \%$

Total number of visualised benign lesions based on biopsy result is73.Total number of lesion visualised in imaging is 22 . No lesions were visualised in 51 cases. Among the lesions visualised, total percentage of benign lesion visualised in central gland $=22.7 \%$; peripheral gland $=63.63 . \%$; both central and peripheral gland $=13.6 \%$

Peripherally located focal lesions were significantly associated with malignancy with $\mathrm{P}$ value of 0.000 and Pearson chi square value of 30.757 . 
Margin of the lesion: Totally 58 focal lesions were present in the examined cases of which ill defined margin was present in 42 cases. Ill defined margin was present in $26.1 \%$ of benign lesions $(n=11)$ and $59.6 \%(n=31)$ of malignant lesions.

\section{Infiltration of lesion into adjacent structures:}

Total number of malignant lesions detected in histopathological result $=49$, Among which $(n=17) 34.6 \%$ of the malignant lesions show infiltration into adjacent structures. . In our study most common site of infiltration was seminal vesicle $(22.4 \%)$ followed by rectum (8.1\%]

Lesions or suspicious areas with increased vascularity: In our study focal lesions or suspicious areas with increased vascularity were considered to be malignant.

Total number of diffusely hypervascular lesions detected in colour doppler imaging were 7. Of which malignancy contributed to $(\mathrm{n}=5 \%) 71.4 \%$ and benign lesions contributed to $(n=2) 28.6 \%$. Total number of focal hypervascular lesions detected in colour doppler imaging were 37 . Of which malignancy contributed to $70.3 \% \quad(n=26)$ and benign lesions contributed to $29.7 \%(n=11)$. Hypervascular areas in colour doppler was significantly associated with malignancy ( $\mathrm{P}$ value $=0.000$ and Pearson chi square value $=26.278)$. Mean value of RI in right capsular artery among benign lesions is 0.6873 and in malignant lesions is 0.6594.Mean value of RI in left capsular artery among benign lesions is 0.6858 and in malignant lesions is 0.6580. Mean value of RI in right urethral artery benign lesions is 0.6777 and in malignant lesions is 0.6733 . Mean value of RI in left urethral artery among benign lesions is 0.6836 and in malignant lesions is 0.6678 .

For right capsular artery resistive index , $\mathrm{P}$ value $=0.193$ and for left capsular artery resistive index $\mathrm{P}$ value $=0.189$ hence no statistically significant difference exist between the resistive index of capsular arteries in benign and malignant lesions. $\mathrm{P}$ value of right urethral artery $=0.836$ and for left $=0.477$ hence no statistically significant difference exist between the resistive index of urethral arteries in benign and malignant lesions.

In our study, the spectral Doppler parameter, Resistive index did not reveal any significant difference in patients with or without prostatic malignancy

Table 4: Statistically significant TRUS parameters favouring malignancy

\begin{tabular}{|l|c|c|}
\hline $\begin{array}{l}\text { TRUS parameters } \\
\text { favouring malignancy }\end{array}$ & P value & $\begin{array}{c}\text { Pearson Chi } \\
\text { - Square }\end{array}$ \\
\hline Presence of focal lesion & 0.000 & 22.075 \\
\hline $\begin{array}{l}\text { Peripheral location of the } \\
\text { lesion }\end{array}$ & 0.000 & 30.757 \\
\hline $\begin{array}{l}\text { ll defined margin of the } \\
\text { lesion }\end{array}$ & 0.000 & 30.807 \\
\hline Irregular Capsular status & 0.000 & 44.883 \\
\hline $\begin{array}{l}\text { Infiltration of adjacent } \\
\text { structures }\end{array}$ & 0.000 & 29.427 \\
\hline
\end{tabular}

Table 5: Statistically Significant Trus Parameters Favouring Malignancy

\begin{tabular}{|lc|l|c|}
\hline $\begin{array}{l}\text { CDI parameter favouring } \\
\text { malignancy }\end{array}$ & P value & $\begin{array}{c}\text { Pearson hi } \\
\text { Square }\end{array}$ \\
\hline
\end{tabular}

\section{Conclusion}

This study was a prospective study conducted in the department of Radio diagnosis, Government Medical College, Kottayam which included the suspicious areas also.

TRUS grey scale parameters such as presence of focal lesion, location of lesion in peripheral gland, ill defined margins of the lesion, capsular irregularity, infiltration of lesion into the adjacent structures were found to be significantly associated with malignancy and median lobe projection was associated with benignity. Hypervascular areas in color doppler was found to be significantly associated with malignancy and equivocal flow The purpose of the present study was to differentiating benign from malignant lesions and to assess the additional advantage of colour with grey scale ultrasound. The final imaging results was correlated with trus guided 12 core biopsy to be significantly associated with benignity.

The sensitivity, specificity, PPV and NPV in our study with transrectal ultrasound versus colour doppler are $75.51 \%$ vs $73.47 \%, \quad 75.34 \%$ vs $80.82 \%, 67.27 \%$ vs $72 \%$ and $82.09 \%$ vs $81.94 \%$. 
Conjunction of color doppler with grey scale ultrasound resulted in increase in sensitivity by 5\% [81.63\%], specificity by 3\%.[78.08\%], Positive Predictive Value by 4\% [71.43\%], and Negative Predictive Value by $4 \%$ [86.36\%] which is still far from that of biopsy results. Hence the study indicates that grey scale and doppler imaging findings alone are not sufficient for completely excluding malignancy. It can be used as an adjunct in evaluating suspicious lesions and as a screening modality to perform targeted biopsy in elderly debilitated males who cannot withstand a regular biopsy. However they cannot be considered as a replacement modality for biopsy which is gold standard.

\section{References}

1. Rumack C. Diagnostic ultrasound. St. Louis: Elsevier Mosby; 2011. Krishnappa, Pravan Kumar Reddy, Anil Kumar Shukla, Harini Boppiah. Role of Transabdominal Sonography as a Screening Tool in Prostatic Diseases. Internal journal on scientific study. 2014;2(7):136-146.

2. Spajic B, Eupic H, Tomas D, Stimac G, Kruslin B, Kraus O. The Incidence of Hyperechoic Prostate Cancer in Transrectal Ultrasound-Guided Biopsy Specimens. Urology. 2007;70(4):734-737.

3. Praveen Kumar P. Chavadi CV. Role of Transrectal ultrasonography and Per rectal examination in the evaluation of prostatic disease: a comparative study International Journal of Biomedical Research [serial on the Internet]. 2015 March 30; [Cited 2015 September 27]; 6(3):[about \#\# p.]. Available from:

http://www.ssjournals.com/index.php/ijbr/arti cle/view/1764

4. R Malik, VK Pandya, D Naik. Transrectal ultrasonography for evaluation of various benign and malignant prostatic lesions and their histopathological correlation. Indian journal of radiology imaging. 2004;14 (2):155-157

5. Abu-Yousef M. Benign prostatic hyperplasia: tissue characterization using suprapubic ultrasound. Radiology. 1985;156(1):169-173.

6. Rifkin M, Friedland G, Shortliffe L. Prostatic evaluation by transrectal endosonography: detection of carcinoma. Radiology. 1986;158(1):85-90.

7. Griffiths G, Clements R, Jones D, Roberts E, Peeling W, Evans K. The ultrasound appearances of prostatic cancer with histological correlation. Clinical Radiology. 1987;38(3):219-227.

8. Lee H, Lee H, Byun S, Lee S, Hong S, Kim S. Classification of Focal Prostatic Lesions on Transrectal Ultrasound (TRUS) and the Accuracy of TRUS to Diagnose Prostate Cancer. Korean Journal of Radiology. 2009;10(3):244.

9. Cho J, Kim S, Lee S. Peripheral Hypoechoic Lesions of the Prostate: Evaluation with Color and Power Doppler Ultrasound. European Urology. 2000;37(4):443-448.

10. B Adhira. Diagnosis of Carcinoma Prostate Based on Transrectal Ultrasound Doppler Findings Validated Against Transrectal Ultrasound Guided Biopsy. Journal of Medical Science And clinical Research [Internet]. 2017;05(03): 19170-19175. Available from: https://dx.doi.org/10.18535/jmscr/v5i3.135

11. Sarkar S, Das S. A Review of Imaging Methods for Prostate Cancer Detection. Biomedical Engineering and Computational Biology. 2016;:1.

12. Louvar E, Littrup P, Goldstein A, Yu L, Sakr W, Grignon D. Correlation of color doppler flow in the prostate with tissue microvascularity. Cancer. 1998;83(1):135-140.

13. Huang ST, Hsieh ML: Evaluation of resistance index in patients with prostate cancer. Anticancer Res.28(4A),1985-1988 (2008). 